His criticism is as forceful and relevant today as it was then. This surely is a more pressing issue for medical educationalists to research. The greatest challenge is to inspire students to curiosity, to fan the flames of their own enthusiasm and the empathy which goes with it. All else will then fall into place.

Dean and Professor of Medicine,

St Mary's Hospital Medical School,

London W2 1PG

I Muzzin LJ, Hart L. Oral examinations. In: Neufeld VR, Norman GR, eds. Assessing clinical competence. New York: Springer, 1985:71-90.

Neufeld VR. An introduction to measurement properties. In: Neufeld VR, Norman GR, eds. Assessing clinical competence. New York: Springer, 1985:39-50.

3 Neufeld VR. Historical perspectives on clinical competence. In: Neufeld VR, Norman GR, eds. Assessing clinical competence. New York: Springer, 1985:3-14

4 Jolly B, Coles C, Norman G, et al. The generalisability of knowledge and the assessment of clinical performance. In: Wakeford R, ed. Directions in clinical assessment. Cambridge: Cambridge University School of Clinical Medicine, 1984:43-54.

5 Norman G, Bordage G, Curry L, et al. A review of recent innovations in assessment. In: Wakeford

$\mathrm{R}$, ed. Directions in clinical assessment. Cambridge: Cambridge University School of Clinical Medicine, 1984:9-27.

6 Glymour C, Stalker G. Engineers, cranks, physicians, magicians. N Engl f Med 1983;308:960-3.

\section{Bereaved children}

The death of a parent is known to be associated with psychological ill health for the child,,$^{1.4}$ but we are unsure how this comes about; the common explanation in adultsproblems in grieving and mourning-is more difficult to establish in children. Indeed, some children do not appear to grieve openly at all. Other uncertainties include whether the effects are short term or delayed ${ }^{5}{ }^{6}$; some evidence suggests that loss of a parent in childhood may be one of the factors associated with later depressive illness. ${ }^{78}$

Such questions are now being answered by controlled studies of children's responses to the death of a parent. ${ }^{9} 10$ These have shown the presence of a "grieving" or dysphoric depressive syndrome expressed through sadness, crying, and irritability combined with sleeping disturbances, nightmares, a general loss of interest, and poor school performance. These patterns are universal in children who are bereaved but are particularly evident in older girls. Younger children may show an additional or perhaps alternative pattern: temper tantrums, fighting, and a diminishment of interest in activities which are normally associated with parents. This may account for apparent lack of a grief reaction. Fortunately, in most children these responses are short term and limited; but any of the patterns may become permanent. Whether they do depends in part on how the children's needs are met and how the adults caring for them respond.

Children seem particularly vulnerable to the state of mental health of the surviving parent. A mother who has been bereaved of her husband may in her own grieving find herself responding with indifference or may fail to be protective, particularly if a specific severe psychiatric state is present. ${ }^{11}$ The age of the child is also important, with loss before the age of 4 particularly stressing. ${ }^{2}$ Which parent has died is another factor. At one time loss of a parent of the same sex was thought to be more distressing than loss of one of the opposite sex. This has not, however, been borne out in recent research. ${ }^{10}$ Husbands who are bereaved seem to recover their own functioning more rapidly than wives. ${ }^{12}$ This may be due to the different social and economic supports available for the surviving parent. The quality of relations within the wider family network both before and after death also has an effect on the child's own ability to cope. Perhaps children try to help by turning their own sadness into activity as a way of not further burdening their parent.

What specific help should we be giving to bereavec $\&^{\circledR}$ families? Studies on adults have shown that difficulty in mourning-in expressing and sharing grief-may have as profound effect on the recovery from bereavement and mayp be one of the factors which can trigger a severe depressives reaction. ${ }^{13}$ The organisation Cruse has played a valuable part in promoting more effective mourning and in helping: adults confront their painful feelings rather than avoiding? them; such activities are known to help avoid long termp mental health hazards. ${ }^{14}$ is

Should similar work be attempted with children and? parents? Black and Urbanowicz have carried out an importan $\mathbb{R}$ controlled study of treatment in which they approacheds families within two months of bereavement and offered six family sessions to help with family problems. ${ }^{16}$ The aim wasto explore feelings and try to help with emotional and practical problems and to facilitate communication and the expression and resolution of grief. Only half of the families. approached wanted help, but the results showed over a 1200 month follow up that children were improved in theiros functioning compared with controls: they had fewer sleepw problems, fewer learning difficulties, were less restless, and were more able to cry and talk about the dead parent. The्c surviving parents were less depressed and seemed to need less help, though there was a universal need expressed for? domestic support in the period after loss, whether the surviving parent was a father or a mother.

These observations suggest that, though children's bereavement responses are limited, their symptoms are important, and the fact that those symptoms are likely to be self limiting should not prevent us promoting the expression of grieto within the family. As professionals we may prefer to avoids the work; we may wish to avoid and postpone such painfu[ issues, but we must be aware that self limiting short termo reactions may become long term in adverse circumstances and may have substantial effects on mental health.

Family based treatment approaches give us means of ameliorating long term distress by promoting the naturapi. resources of the family. We should begin to think of how this can be achieved in a systematic and broadly based fashion.

Consultant Psychiatrist, ARNON BENTOVIM

Hospital for Sick Children

Great Ormond Street,

London WCIN 3JH

1 Bowlby J. Loss: sadness and depression. Attachment and loss. Vol 3. London: Hogarth Press, 19800 2 Rutter M. Bereaved children "children of sick parents." London: Oxford University Press, 1966

(Maudsley monograph XVI.) and later behavior disorder hypothesis. In: Fulton R, ed. Death and identizy. Bowie, Maryland

Charles Press, 1976.
Markusen E, Fulton R. Childhood bereavement and behaviour disorders; a critical review. Omego 1971;2:107-17.

5 Gregory I. Anterospective data following loss of a parent. Arch Gen Psychiatry 1965;13:99-109.

6 Gregory I. Anterospective data following loss of a parent. Arch Gen Psychiatry 1965;13:110-20. \&

Birtchnell J. Women whose mothers died in childhood: an outcome study. Psychol Med 1980;10:699-713.

8 Brown G, Harris T. Social origins of depression. London: Tavistock, 1978.

Van Eerdewegh MM, Bieri M, Parrilla RH, Clayton PJ. The bereaved child. Br f Psychiarn 1982;140:23-9.

10 Van Eerdewegh MM, Clayton PJ, Van Eerdewegh P. The bereaved child; variables influencing early psychopathology. Br f Psychiatry 1985; 147:188-94.

1 Marris P. Widows and their families. London: Routledge, 1958.

12 Parkes CM. Bereavement: studies of grief in adult life. London: Tavistock, 1972

13 Parkes CM. Determinants of outcome following bereavement. Omega 1975;6:303-23.

14 Raphael B, Maddison D. The care of bereaved adults. In: Hill OW, ed. Modern trends in psychosomatic medicine: 3. London: Butterworth, 1976.

15 Lieberman S. Nineteen cases of morbid grief. Br f Psychiatry 1978;132:159-70.

16 Black D, Urban. research in developmental psychopathology. Oxford: Pergamon Press, 1984 